\title{
Transport-induced mortality in Pekin ducks transported for slaughter in the Czech Republic
}

\author{
Eva Voslářová ${ }^{1}$, Tatána Hytychová ${ }^{1}$, Vladimír Večerek ${ }^{1}$, Katarina Nenadovic ${ }^{2}$, \\ Iveta Bedáňová ${ }^{1}$ \\ ${ }^{1}$ University of Veterinary and Pharmaceutical Sciences Brno, Faculty of Veterinary Hygiene and Ecology \\ Department of Animal Protection, Welfare and Behaviour, Brno, Czech Republic \\ ${ }^{2}$ University of Belgrade, Faculty of Veterinary Medicine, Department of Animal Hygiene, Belgrade, Serbia \\ Received September 21, 2015 \\ Accepted May 2, 2016
}

\begin{abstract}
Data on the numbers of Pekin ducks transported to slaughterhouses between 2009 and 2014 and the numbers of ducks that died during these transports were recorded in cooperation with the State Veterinary Administration of the Czech Republic. In the monitored period, a total of 12,327,017 ducks were transported, of which 9,545 $(0.077 \%)$ died. The levels of transport-related mortality over these years varied significantly $(P<0.001)$; the lowest mortality was observed in $2011(0.059 \%)$ and the highest in $2013(0.089 \%)$. The impact of distance on transport-related mortality in ducks was demonstrated. The lowest transport-related mortality $(0.052 \%)$ was found for distances shorter than 50 $\mathrm{km}$. It was significantly $(P<0.001)$ lower than the mortality rates connected with longer journeys. The greatest mortality rates were found for transport distances of $101-200 \mathrm{~km}(0.105 \%)$. In addition, the season of the year significantly affected transport-related mortality in Pekin ducks. The highest death losses were found in the summer $(0.090 \%)$. Death losses of ducks connected with summer transports were significantly higher $(P<0.001)$ in comparison with transport-related mortality rates in any other season of the year. The lowest death losses were found in duck transports carried out in the autumn and winter $(0.069 \%$ and $0.072 \%$, respectively) with no significant difference between those two seasons. Shortening transport distances and maintaining a suitable micro-climate inside transport vehicles especially in the summer are thus two important factors that can contribute to reducing transportrelated mortality in Pekin ducks in commercial practice.
\end{abstract}

Poultry, transport, death on arrival, season, distance, welfare

Transportation is regarded as a major stressor for livestock and may have harmful effects on their health, well-being, performance, and the resulting quality of products (von Borell 2001). During transit poultry can be exposed to a variety of potential stressors that may lead to death. Poultry mortality related to transport to the slaughterhouse or acts that are linked with it are reported in many studies. Most studies deal with deaths identified on arrival in broiler chickens (Tabba and Alshawabkeh 2000; Nijdam et al. 2004; Petracci et al. 2006; Večerek et al. 2006; Voslář́ová et al. 2007b; Oba et al. 2009; Vieira et al. 2011). Death on arrival of other poultry species and categories was studied to a lesser extent. In the study of Voslářová et al. (2007b) the highest mortality rate was found in hens and roosters $(1.013 \%)$, the second highest, i.e. $0.272 \%$, was found in turkeys and the third place was occupied by the aforementioned broiler mortality. The study reported $0.103 \%$ ducks and $0.056 \%$ geese found dead on arrival (DOA). Petracci et al. (2006) also found the highest DOA in spent hens (1.22\%) and DOAs of broiler chickens and turkeys were similar in their studies. Voslářová et al. (2007a) found $0.925 \%$ of DOA in hens and roosters. Voslářová et al. (2006) determined $0.18-0.37 \%$ (variation with travel distance and month) of DOA in turkeys. There are some studies on the factors associated with the transport of Pekin ducks to the slaughterhouse (Fernandez et al. 2001; Zhu et al. 2014) and their DOA (Voslářová et al. 2007b) but to our knowledge the number of studies on this topic is very limited. 
The aim of the present study was to assess mortality related to the commercial transport of Pekin ducks for slaughter in the Czech Republic; to determine the effect of transport distance and season on duck mortality, and, in addition, to identify developmental trends in the numbers of ducks dying in the process of being transported for slaughter in the monitored period.

\section{Materials and Methods}

In the period from 2009 to 2014 , the transport of Pekin ducks to slaughterhouses was monitored in the Czech Republic; particularly, the numbers of ducks transported and the numbers of ducks dying during transport or in the slaughterhouse after transport.

The impact of distance on the ducks' mortality in relation to transport to the slaughterhouse was determined in such a way that the transport distances were divided into distances of up to $50 \mathrm{~km}, 51 \mathrm{~km}$ to $100 \mathrm{~km}, 101 \mathrm{~km}$ to $200 \mathrm{~km}, 201 \mathrm{~km}$ to $300 \mathrm{~km}, 301 \mathrm{~km}$ to $400 \mathrm{~km}$, and above $400 \mathrm{~km}$. For these transport distances, the annual numbers of transported ducks and the annual numbers of duck deaths were recorded in absolute numbers and mortality was calculated in percentages for the period from 2009 to 2014.

Seasonal impact as shown by the four seasons: spring (March, April, May), summer (June, July, August), autumn (September, October, November) and winter (December, January, February) on duck mortality during transport to the slaughterhouse was determined in such a way that for the individual seasons for the whole monitored period, the total numbers of transported ducks and the total numbers of duck deaths were determined and mortality was calculated in percentages for the period from 2009 to 2014 .

Data were analysed using the statistical package Unistat v. 6.5. (Unistat Ltd., GB). Statistical comparisons between frequencies of the categorical variables of interest were performed with Chi-square test (with Yates correction when necessary) within the contingency table procedure. When the frequencies in the contingency table were lower than 5, Fisher's exact test was used instead of Chi-square test. Data concerning transport-related mortality rates in ducks were compared between individual years and transport distances monitored in the study, and differences in mortality rates between the seasons were tested for the whole period from 2009 to 2014 . A $P$ value of 0.05 in tests was considered significant.

\section{Results}

During the monitored period, a total of 12,327,017 Pekin ducks were transported to slaughterhouses in the Czech Republic, with 9,545 transport-related deaths reported. The mean number of transported ducks per year was 2,054,503 and 1,591 ducks died on average per year in connection with their transport for slaughter. The absolute numbers of transported ducks and duck deaths for the monitored distances are reported in Table 1. During the six-year period an overall mortality rate of $0.077 \%$ was observed.

Table 1. The numbers of ducks transported to slaughterhouses and numbers of ducks deaths as a result of their transport for monitored distances.

\begin{tabular}{llllllll}
\hline $\begin{array}{c}\text { Distance } \\
(\mathrm{km})\end{array}$ & 2009 & 2010 & $\begin{array}{c}2011 \\
\text { Number of ducks }\end{array}$ & \multicolumn{2}{c}{2012} & 2013 & 2014 \\
\hline$<50$ & transported & 573,533 & 528,571 & 522,092 & 546,367 & 644,964 & $1,146,708$ \\
& dead & 230 & 264 & 229 & 281 & 380 & 692 \\
$51-100$ & transported & 978,395 & 666,466 & 387,102 & 323,574 & 338,331 & 305,463 \\
& dead & 702 & 371 & 195 & 200 & 218 & 195 \\
$101-200$ & transported & $1,318,691$ & $1,126,156$ & 574,630 & 570,335 & 762,655 & 772,581 \\
& dead & 1557 & 971 & 457 & 588 & 952 & 845 \\
$201-300$ & transported & 124,952 & 61,880 & 0 & 0 & 0 & 53,571 \\
& dead & 93 & 57 & 0 & 0 & 0 & 68 \\
\hline
\end{tabular}

In Fig. 1, trends in the duck transport related mortality rates are shown. Death losses were the lowest in $2011(0.059 \%)$, and the highest in $2013(0.089 \%)$. The transport-related 


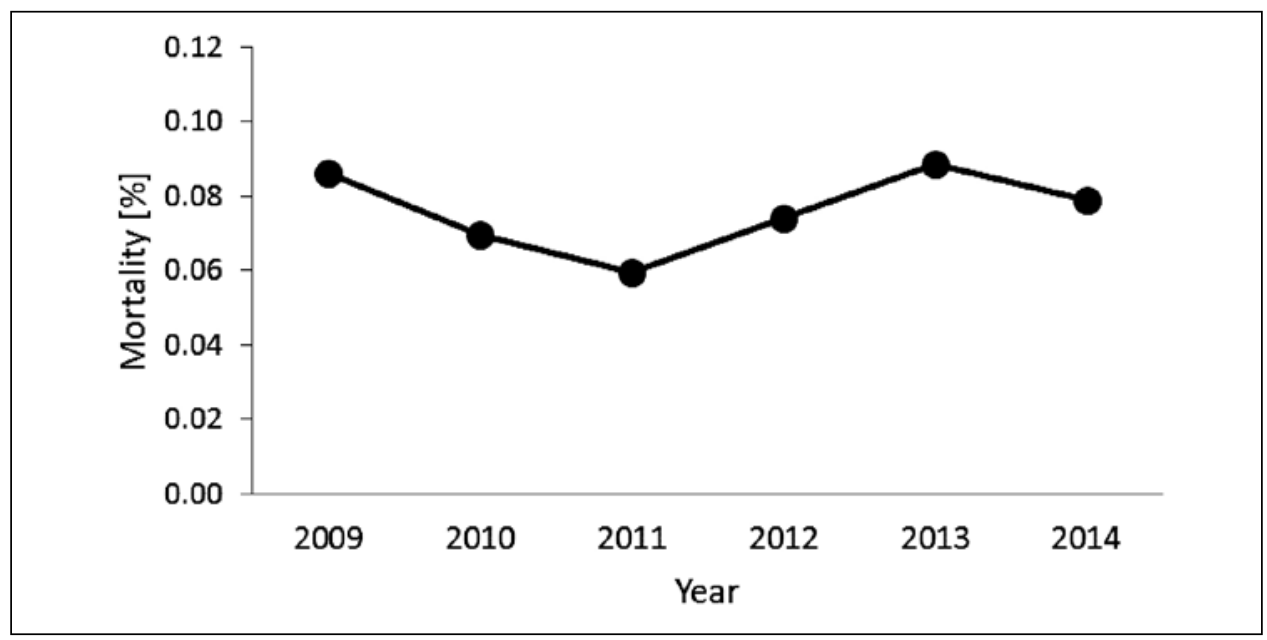

Fig. 1. Trends in the transport-related mortality in ducks in the period from 2009 to 2014 .

mortality rates in Pekin ducks differed significantly $(P<0.001)$ between the individual years of the monitored period. Whereas from 2009 to 2011 mortality seemed to be decreasing, a rising trend was found subsequently with a decline in 2014.

Mortality rates as affected by the transport distance are presented in Fig. 2. The lowest transport-related mortality $(0.052 \%)$ was found for distances shorter than $50 \mathrm{~km}$. It was significantly $(P<0.001)$ lower than the mortality rates connected with longer journeys. The greatest mortality rates were found for transport distances of $101-200 \mathrm{~km}(0.105 \%)$.

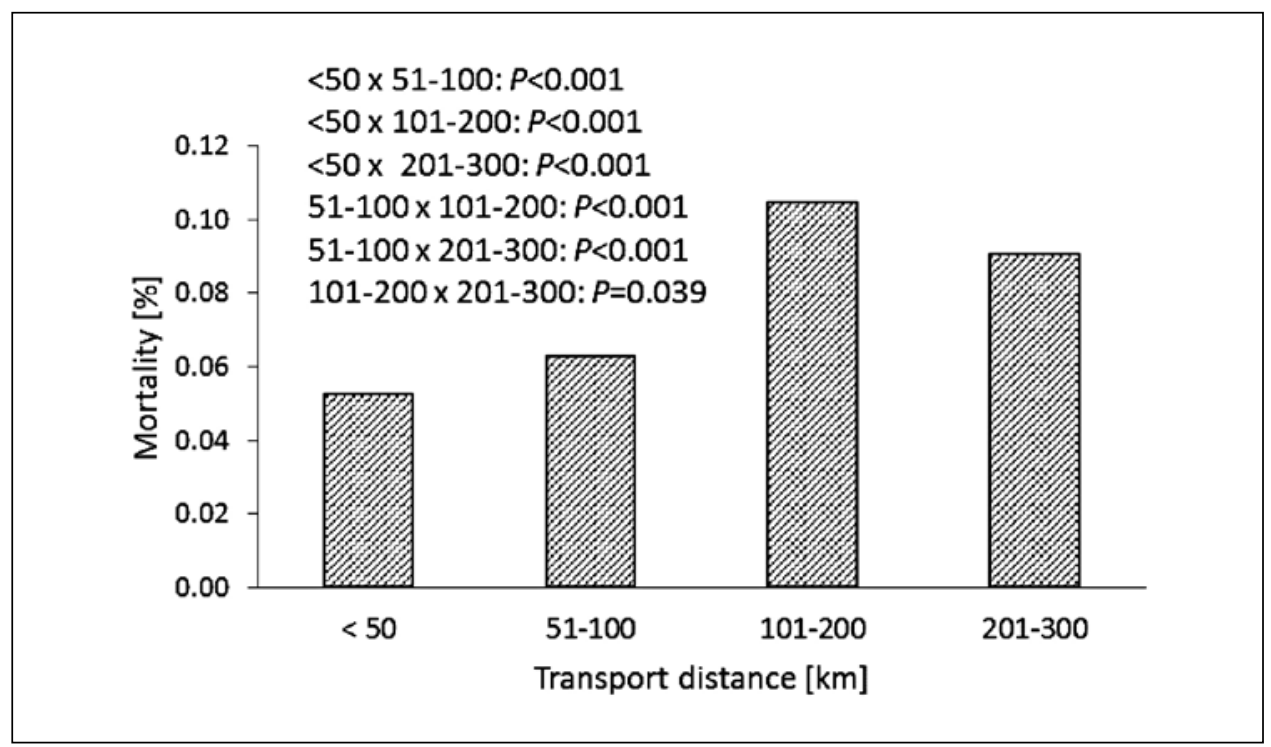

Fig. 2. Transport-related mortality of ducks in relation to transport distance in the period from 2009 to 2014. 
Table 2. The numbers of ducks transported to slaughterhouses and numbers of duck deaths as a result of their transport for monitored seasons of the year.

\begin{tabular}{llllllll}
\hline $\begin{array}{c}\text { Distance } \\
(\mathrm{km})\end{array}$ & 2009 & 2010 & $\begin{array}{c}2011 \\
\text { Number of ducks }\end{array}$ & \multicolumn{2}{c}{2012} & 2013 & 2014 \\
\hline Spring & transported & 749,779 & 689,863 & 408,865 & 315,817 & 389,963 & 523,945 \\
& dead & 843 & 453 & 223 & 218 & 423 & 344 \\
Summer & transported & 633,471 & 507,751 & 301,568 & 310,482 & 454,053 & 566,419 \\
& dead & 661 & 399 & 200 & 226 & 491 & 518 \\
Autumn & transported & 909,682 & 445,387 & 364,115 & 502,009 & 527,171 & 693,160 \\
& dead & 569 & 244 & 203 & 392 & 387 & 567 \\
Winter & transported & 702,639 & 740,072 & 409,276 & 311,968 & 374,763 & 494,799 \\
& dead & 509 & 567 & 255 & 233 & 249 & 371 \\
\hline
\end{tabular}

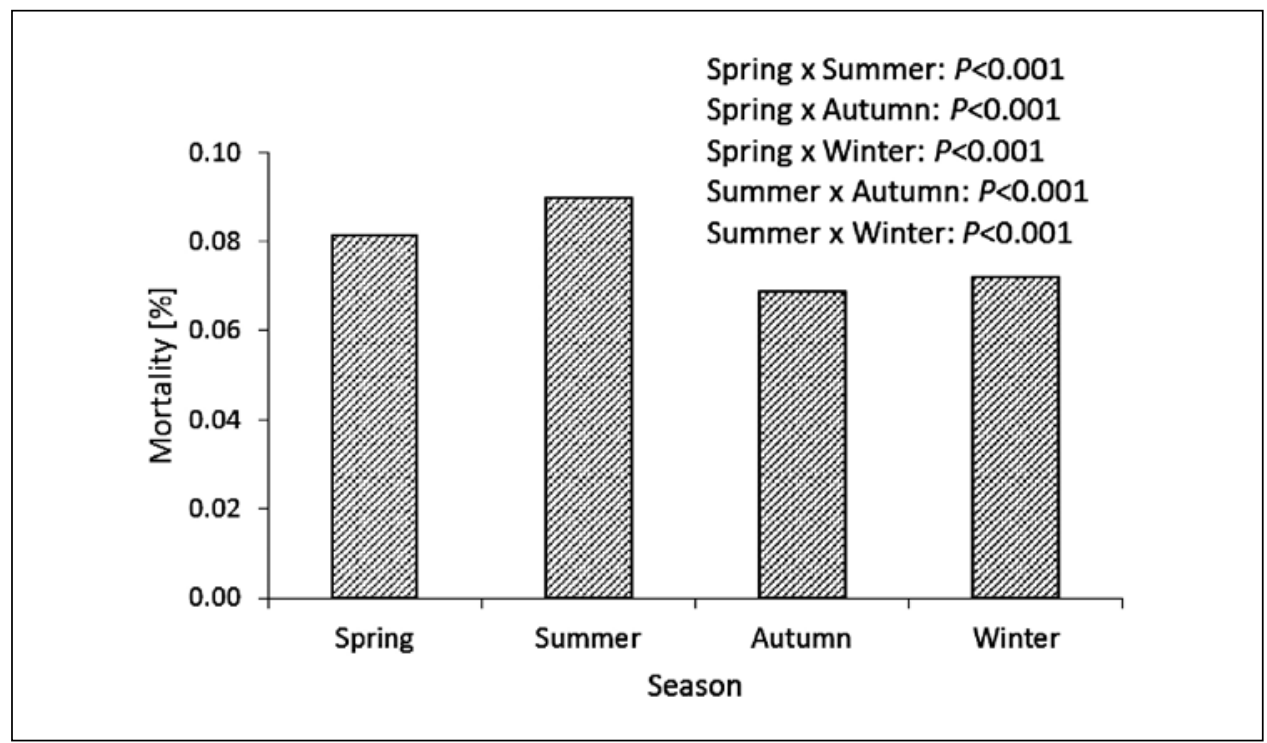

Fig. 3. Transport-related mortality of ducks in relation to the season of the year in the period from 2009 to 2014.

The absolute numbers of transported ducks and duck deaths for the monitored seasons of the year are given in Table 2. The transport-related mortality of ducks in relation to the season of the year is summarized in Fig. 3. The lowest death losses were found in duck transports carried out in the autumn and winter $(0.069 \%$ and $0.072 \%$, respectively) with no significant differences between those two seasons. The highest death losses were found in the summer $(0.090 \%)$. Death losses of ducks connected with summer transports were significantly higher $(P<0.001)$ compared to transport-related mortality rates in any other season of the year.

\section{Discussion}

Ducks rank second among the poultry species most frequently used for meat production in the Czech Republic, by the number of birds annually transported to slaughterhouses 
(Voslářová et al. 2007b). In the period monitored, the mean number of ducks annually transported to slaughterhouses $(2,054,503)$ was very similar to that reported earlier by Vos lářová et al. (2007b) in their study analysing the transport of poultry to slaughterhouses between 1997 and 2006. The mean annual mortality rate reported in the present study $(0.077 \%)$ is, however, significantly lower than the mean transport-related mortality published in the aforementioned study $(0.103 \%)$. This positive finding demonstrates the effect of the trend of increasing emphasis on ensuring the welfare of animals on farms as well as during their transport to slaughter with the knowledge that these conditions also directly reflect in the quality of the final product. In spite of that, transport-related mortality rates showed significant variations in individual years during our monitored period, with marked year-on-year increases in death losses of birds in transit in 2012 and 2013. Bird welfare generally is a challenge for the poultry industry, and the main theme in this respect is proper management, because farmers are aware that they have to handle poultry so as to avoid stress conditions that induce meat quality deterioration, e.g. PSE (pale, soft, exudative) meat, and deaths during transport (Mitchell and Kettlewell 1998; Barbut et al. 2008). Modern fast-growing poultry hybrids for meat production have a higher incidence of spontaneous or idiopathic myopathy and increased susceptibility to stress-induced myopathy (Mitchell 1999; Sandercock and Mitchell 2003; Sandercock et al. 2006). Muscle myopathy may be due to violent handling during loading to which the animals respond with increased energy expenditure (Ebedes et al. 2002a). Stress and rough handling during loading, and transport may thus affect the health and quality of products from slaughtered animals. Traumas resulting from improper handling were described by Weeks and Nicol (2000) who reported up to $23 \%$ of laying hens with broken limbs after they were unloaded from the transport crate. Gregory and Austin (1992) found that trauma was the cause of death of $35 \%$ of broilers dead on arrival to the six processing facilities they were monitoring. Monitoring broilers during live haul, Ritz et al. (2005) observed that injuries inflicted to the birds during loading and handling were the primary cause of their death on arrival at the slaughterhouse. The situation may be further exacerbated in the case of domestic ducks. According to Henders on et al. (2001), domestic ducks show fear response in the presence of humans, which may lead not only to injuries, but even death by suffocation of the birds if they get piled on each other. Another adverse consequence of pre-slaughter stress can be increased microbial contamination of animals. Mengert et al. (1998) found that the levels of endogenous microbial contamination in stressed ducks were more than $30 \%$ higher than in the control group. In their study, Nijdam et al. (2006) reported macroscopic pathological lesions in $89.4 \%$ of dead broilers on arrival at the processing plant. The main causes of lesions $(64.9 \%)$ were infectious diseases, followed by heart and the circulatory system disorders (42.4\%) and injuries $(25 \%)$.

During transport to the slaughterhouse, poultry is exposed to many stress-inducing factors such as packing density, microclimatic conditions, vehicle acceleration, vibrations, movement, noise, disruption of social bonds, transport time, transport distance and the season of the year (Nicol and Scott 1990; Mitchell and Kettlewell 1993; Mitchell and Kettlewell 1998; Carlisle et al. 1998; Hunter et al. 1999, 2001; Abeyesinghe et al. 2001; Nijdam et al. 2004; Warriss et al. 2005, Večerek et al. 2006; Voslářová et al. 2007a,b). One of the important factors affecting poultry welfare during live haul is the transport distance. Longer transport distances are commonly associated with increased stress load, and often with increased numbers of birds dying during transport (Warriss et al. 1992; Warriss and Brown 1996; Nijdam et al. 2004; Petracci et al. 2005; Večerek et al. 2006; Voslářová et al. 2006; Voslářová et al. 2007a,b). The distances for which ducks were transported to slaughter changed significantly in the period monitored. Since the 2009-2013 period when most ducks were transported over distances of 101-200 km, the numbers of ducks transported over distances shorter than $50 \mathrm{~km}$ gradually increased 
and, in 2014, short transport distances already predominated. This may be related to the consolidation of the farm locations and slaughter plants, which has an ultimately positive impact also on the welfare of ducks during transport. Our study showed that transport over short distances (up to $50 \mathrm{~km}$ ) is associated with the lowest duck mortality $(0.052 \%)$, whereas the highest mortality rate was found for transport distances of 101-200 km $(0.105 \%)$. Transporting ducks to slaughter over distances exceeding $200 \mathrm{~km}$ nowadays happens only very rarely in our conditions. In fact, no ducks were transported for such distances between 2011 and 2013, which is a positive development given the fact that such long transport distances in the previous period were associated with a high mortality rate $(0.147 \%)$, as reported by Voslářová et al. (2007b). Elimination of long transport distances was probably one of the factors that contributed to the overall reduction in transport-related mortality in ducks found in our study. In their study of transport stress, Zhu et al. (2014) investigated the effects of travel distances $(1,2$ or $3 \mathrm{~h}$ ) and the lairage time (30 min to 2 h) on certain blood indicators and meat quality. They found that a two-hour transport is the most stressful for ducks. The negative effects of transport are, however, mitigated by a two-hour rest before slaughter.

Another factor monitored was the influence of the ambient temperature, or, rather, the season of the year when the transport took place, on the level of transport-related mortality in ducks. In warm seasons, i.e. in the spring and summer, mortality rates recorded in our study were higher $(0.081 \%$ and $0.090 \%$, respectively) than in the cold seasons of the year, i.e. in the autumn and winter $(0.069 \%$ and $0.072 \%$, respectively). At high or very low outdoor temperatures, important microclimatic changes take place inside transport trucks unequipped with air-conditioning. The internal thermal micro-environment in poultry transport containers is the product of the inlet air temperature and humidity, airflow rate and the heat and moisture production of the birds (Mitchell et al. 2000; Kettlewell and Mitchell 2001a,b; Mitchell 2006). Probably the only published data on heat production by poultry under transport conditions, based on field measurements rather than on predictive models, are the data for broiler chickens (Kettlewell et al. 2000). Measurements of temperature, relative humidity and the concentration of carbon dioxide were conducted on the inlets and outlets of the transport vehicle for a known set ventilation rate. It took much longer for heat produced by broilers to stabilize on an unventilated trailer than on a trailer with fan ventilation. They also found that lower outside temperatures led to a decrease in the rectal temperature of birds near the air inlet, and, consequently, to excessive heat production. Fan ventilation on vehicles is therefore necessary, but the inflow of cold air should not be too strong.

The fast growing poultry strains may manifest reduced thermoregulatory capability compared to their genetic ancestors and can be therefore more susceptible to heat stress during transport and subsequent problems, including muscle damage, acid-base disturbances and reduced quality of meat (Sandercock et al. 2001, 2006). Genetic selection for faster growth and better feed conversion may be associated with altered mitochondrial function (Bottje et al. 2006) and changes in the production of reactive oxygen species. In this context, it has been demonstrated that acute heat stress increases the production of superoxide free radicals in the skeletal muscle of chickens (Mujahid et al. 2005). This process is mediated by altered mitochondrial function and deregulation of the „disconnecting protein content“. This mechanism may be responsible for transport stress and heat-stress induced muscle damage and changes in the quality of meat that have been observed in broilers (Mujahid et al. 2006, 2007). To our knowledge, no such research has been carried out for ducks, but it can be assumed that a similar stress mechanism will also exist in their case. The model developed by Nijdam et al. (2004) indicates that temperature multiplied by transport time is an important determinant affecting the overall DOA levels as are transport time per se and lairage time. 
In conclusion, a decrease in the number of ducks transported over long distances was observed during the monitored period. The numbers of ducks transported over distances shorter that $50 \mathrm{~km}$ gradually increased, and in 2014 these short-distance transports completely predominated. It is a positive trend from the viewpoint of duck welfare during transport, since transport over short distances is associated with the lowest duck mortality. However, the year-on-year comparison failed to show a significant decrease in transport-related mortality in ducks during the monitored period, which is probably due to other factors. One of them may be unsuitable micro-climatic conditions especially in the summer, when the transport-related death rate among ducks is high. Taking these two factors into consideration may be an important strategic step towards reducing transportrelated mortality in Pekin ducks in commercial practice.

\section{References}

Abeyesynghe SM, Wathes CM, Nicol CJ, Randall JM 2001. The aversion of broiler chickens to concurrent vibrational and thermal stressors. Appl Anim Behav Sci 73: 199-215

Barber CL, Prescott NB, Wathes CM, Le Sueur C, Perry GC 2004. Preferences of growing ducklings and turkey poults for illuminance. Anim Welfare 13: 211-24

Barbut S, Sosnicki AA. Lonergan SM, Knapp T, Ciobanu DC, Gatcliffe LJ, Huff-Lonergan E, Wilson EW 2008. Progress in reducing the pale, soft and exudative (PSE) problem in pork and poultry meat. Meat Sci 79: 46-63

Bottje W, Pumford NR, Ojano-Dirian C, Iqbal M, Lassiter K 2006. Feed efficiency and mitochondrial function. Poult Sci 85: 8-14

Carlisle AJ, Mitchell MA, Hunter RR, Duggan JA, Randall JM 1998. Physiological responses of broiler chickens to the vibrations experienced during road transportation. Brit Poult Sci 39: 48-60

Ebedes H, Van Rooyen J, Du Toit JG 2002. Capturing wild animals. In: Bothma JP (Ed.): Game Ranch Management, Van Scheik, Pretoria, South Africa: 382-440

Fernandez X, Bouillier-Oudot M, Molette C, Bernadet MD, Manse H 2011. Duration of transport and holding in lairage at constant postprandial delay to slaughter - Effects on fatty liver and breast muscle quality in mule ducks. Poult Sci 90: 2360-2369

Gregory NG, Austin SD 1992. Causes of trauma in broilers arriving dead at poultry processing plants. Vet Rec 131: $501-503$

Henderson JV, Nicol CJ, Lines JA, White RP, Wathes CM 2001. Behaviour of domestic ducks exposed to mobile predator stimuli. 1. Flock responses. Brit Poult Sci 42: 433-8

Hunter RR, Mitchell MA, Carlisle AJ 1999. Wetting of broilers during cold weather transport; a major source of physiological stress. Brit Poult Sci 40: 48-49

Hunter RR, Mitchell MA, Matheu C 2001. Mortality of broiler chickens in transit - correlation with the thermal micro-environment. In: Proceedings of the $6^{\text {th }}$ International Livestock Environment Symposium, Louisville, Kentucky, USA, 21-23 May 2001: 542-549

Kettlewell PJ, Hoxey RP, Mitchell MA 2000. Heat produced by broiler chickens in a commercial transport vehicle. J Agr Eng Res 75: 315-326

Kettlewell PJ, Mitchell MA 2001a. Comfortable ride: Concept 2000 provides climate control during poultry transport. Resour Eng Technol Sustain World 8: 13-14

Kettlewell PJ, Mitchell MA 2001b. Mechanical ventilation: Improving the welfare of broiler chickens in transit. J Roy Agric Soc 162: 175-184

Mengert U, Fehlhaber K, Arwana AA 1998. Investigating stress-induced endogenous microbial contamination of Muscovy ducks in connection with feeding Zinc-bacitracin. Arch Geflugelkd 62: 49-54

Mitchell MA 1999. Muscle abnormalities - pathophysiological mechanisms. In: Richardson, RI, Mead GC (Eds): Poultry Meat Sci. Poultry Sci. Symposium Series Vol. 25, CABI Publishing, CABI International, Oxon, UK: 65-98

Mitchell MA 2006. Influence of pre-slaughter stress on animal welfare and processing efficiency. Worlds Poult Sci J 62: 254

Mitchell MA, Carlisle AJ, Hunter RR, Kettlewell PJ 2000. The responses of birds to transportation. In: Proceedings of the World Poultry Congress, Montreal, Canada, 22-24 August 2000: 1-14

Mitchell MA, Kettlewell PJ 1993. Catching and transport of broiler chickens. In: Proceedings of the Fourth European Symposium on Poultry Welfare. Savory CJ \& Hughes BO (Eds), Universities Federation for Animal Welfare: $219-229$

Mitchell MA, Kettlewell PJ 1994. Road transportation of broiler-chickens - induction of physiological stress. Worlds Poult Sci J 50: 57-59

Mitchell MA, Kettlewell PJ 1998. Physiological stress and welfare of broiler chickens in transit: Solutions not problems! Poult Sci 77: 1803-1814 
Mujahid A, Yoshiki Y, Akiba Y, Toyomizu M 2005. Superoxide radical production in chicken skeletal muscle induced by acute heat stress. Poult Sci 84: 307-314

Mujahid A, Sato K, Akiba Y, Toyomizu M 2006. Acute heat stress stimulates mitochondrial superoxide production in broiler skeletal muscle, possibly via down-regulation of uncoupling protein content. Poult Sci 85: 1259-1265

Mujahid A, Akiba Y, Toyomizu M 2007. Acute heat stress induces oxidative stress and decreases adaptation in young white leghorn cockerels by downregulation of avian uncoupling protein content. Poult Sci 86: 364-371

Nicol CJ, Scott GB 1990. Pre-slaughter handling and transport of broiler chickens. Appl Anim Behav Sci 28: 57-73

Nijdam E, Arens P, Lambooij E, Decuypere E, Stegman JA 2004. Factors influencing bruises and mortality of broilers during catching, transport and lairage. Poult Sci 83: 1610-1615

Nijdam E, Zailan ARM, van Eck JHH, Decuypere E, Stegman JA 2006. Pathological features in dead on arrival broilers with special reference to heart disorders. Poult Sci 85: 1303-1308

Oba A, de Almeida M, Pinheiro JW, Ida EI, Marchi DF, Soares AL, Shimokomaki M 2009. The effect of management of transport and lairage conditions on broiler chicken breast meat quality and DOA (Death on Arrival). Braz Arch Biol Techn 52: 205-211

Petracci M, Fletcher DL, Northcutt JK 2001. The effect of holding temperature on live shrink, processing yield, and breast meat quality of broiler chickens. Poult Sci 80: 670-675

Petracci M, Bianchi M, Cavani C 2005. Pre-slaughter factors affecting mortality, live weight loss, and carcass quality in broiler chickens. XVII ${ }^{\text {th }}$ European Symposium on the Quality of Poultry Meat Doorwerth, The Netherlands, 23-26 May 2005: 251-255

Petracci M, Bianchi M, Cavani C, Gaspari P, Lavazza A 2006. Preslaughter Mortality in Broiler Chickens, Turkeys, and Spent Hens Under Commercial Slaughtering. Poult Sci 85: 1660-1664

Ritz C, Fairchild B, Lacy M 2005. Litter quality and broiler performance. Cooperative Extension Service, University of Georgia College of Agricultural and Environmental Sciences. http://pubs.caes.uga.edu/caespubs/pubcd/B1267. htm. Accessed January 15, 2008

Ritz CW, Webster AB, Czarick M 2005. Evaluation of hot weather thermal environment and incidence of mortality associated with broiler live haul. J Appl Poult Res 14: 594-602

Sandercock DA, Hunter RR, Nute GR, Mitchell MA, Hocking PM 2001. Acute heat stress-induced alterations in blood acid-base status and skeletal muscle membrane integrity in broiler chickens at two ages: Implications for meat quality. Poult Sci 80: 418-425

Sandercock DA, Mitchell MA 2003. Myopathy in broiler chickens: A role for Ca2+-activated phospholipase A2? Poult Sci 82: 1307-1312

Sandercock DA, Hunter RR, Mitchell MA, Hocking PM 2006. Thermoregulatory capacity and muscle membrane integrity are compromised in broilers compared with layers at the same age or body weight. Brit Poult Sci 47: 322-329

Tabbaa MJ, Alshawabkeh K 2000. Some factors affecting preslaughtering mortality and damage to broilers and interaction during transportation to processing plants. Dirasat Agric Sci 27: 375-384

Večerek V, Grbalová S, Voslářová E, Janáčková B, Malena M 2006. Effects of travel distance and the season of the year on death rates of broilers transported to poultry processing plants. Poult Sci 85: 1881-1884

Vieira FMC, Silva IJO, Barbosa Filho JAD, Vieira AMC, Broom DM 2011. Preslaughter mortality of broilers in relation to lairage and season in a subtropical climate. Poult Sci 90: 2127-2133

Von Borell EH 2001. The biology of stress and its application to livestock housing and transportation assessment. J Anim Sci 79: 260-267

Voslářová E, Janáčková B, Vitula F, Kozák A, Večerek V 2007a. Effects of transport distance and the season of the year on death rates among hens and roosters in transport to poultry processing plants in the Czech Republic in the period from 1997 to 2004. Vet Med-Czech 52: 262-266

Voslářová E, Janáčková B, Rubešová L, Kozák A, Bedáňová I, Steinhauser L, Večerek V 2007b. Mortality rates in poultry species and categories during transport for slaughter. Acta vet Brno 76: 101-108

Voslářová E, Rubešová L, Večerek V, Pištěková V, Malena M 2006. Variation in the mortality rate of turkeys during transport to the slaughterhouse with travel distance and month. Berl Munch Tierarztl Wochenschr 119: 386-390

Warriss PD, Bevis EA, Brown SN 1990. Time spent by broiler chickens in transit to processing plants. Vet Rec 127: 617-619

Warriss PD, Bevis EA, Brown SN, Edwards JE 1992. Longer journeys to processing plants are associated with higher mortality in broiler chickens. Brit Poult Sci 3: 201-206

Warriss PD, Brown SN 1996. Time spent by turkeys in transit to processing plants. Vet Rec 139: 72-73

Warriss PD, Bevis EA, Brown SN, Edwards JE 1992. Longer journeys to processing plants are associated with higher mortality in broiler-chickens. Brit Poult Sci 33: 201-206

Warriss PD, Pagazaurtundua A, Brown SN 2005. Relationship between maximum daily temperature and mortality of broiler chickens during transport and lairage. Brit Poult Sci 46: 647-651

Zhu Z, Chen Y, Huang Z, Zhang Y, Xu Q, Tong Y, Zhai F, Chang G, Chen G 2014. Effects of transport stress and rest before slaughter on blood parameters and meat quality of ducks. Can J Anim Sci 94: 595-600 